GuILLERMINA FERnÁNDEZ Lic. en Geografía. Máster en Gestión Pública de Turismo. Docente de la Facultad de Ciencias Humanas, Universidad Nacional del Centro de la provincia de Buenos Aires. Investigadora del Centro de Investigaciones y Estudios Ambientales.

Buenos Aires, Argentina [guillerminafernandezzambon@gmail.com] Aldo Ramos

Licenciado en Geografía. Máster en Ecoauditorías y Planificación de Medio Ambiente. Docente de la Facultad de Ciencias Humanas, Universidad Nacional del Centro de la provincia de Buenos Aires. Investigador del Centro de Investigaciones y Estudios Ambientales. Buenos Aires, Argentina. [aldogramos@gmail.com] Silvia VAlenzUELA

Profesora de Geografía. Máster en Evaluación de Impacto Ambiental. Docente de la Facultad de Ciencias Humanas, Universidad Nacional del Centro de la provincia de Buenos Aires. Investigadora de Centro de Investigaciones y Estudios Ambientales. Buenos Aires, Argentina. [sivale62@gmail.com] SuSANA RıcCl

Doctora en Ciencias Naturales. Docente de la Facultad de Ciencias Humanas, Universidad Nacional del Centro de la provincia de Buenos Aires. Investigadora de Centro de Investigaciones y Estudios Ambientales. Buenos Aires, Argentina. [susanariccih@gmail.com]

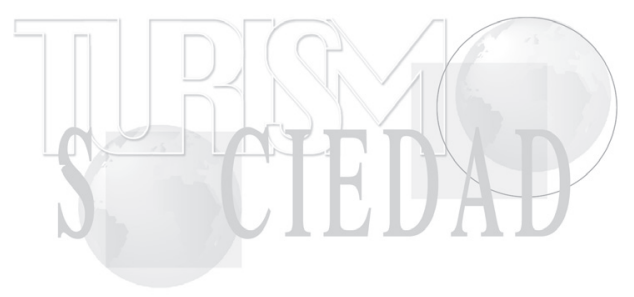

\section{GEODIVERSIDAD, PATRIMONIO MINERO Y GEOTURISMO: PROPUESTA DE PARQUE GEOMINERO EN ARGENTINA ${ }^{1}$}

\section{GEODIVERSITY, MINING HERITAGE AND GEOTOURISM: PROPOSED GEO-MINING PARK IN ARGENTINA}

1 Fecha de recepción: 15/04/2015

Fecha de modificación: 04/06/2015

Fecha de aceptación: 15/07/2015

Para citar el artículo: Fernández, G., Ramos, A., Valenzuela, S. y Ricci, S. (2015). Geodiversidad, patrimonio minero y geoturismo: propuesta de parque geominero en Argentina, Turismo y Sociedad, XVII, pp. 17-37 DOI: http://dx.doi. org/10.18601/01207555.n17.02

\section{Resumen}

En las últimas décadas, el patrimonio minero ha adquirido cada vez mayor importancia desde el punto de vista de su valor social y desde las actividades turísticas, relevancia que se ha manifestado a la par con el surgimiento de la necesidad de conservar y proteger la geodiversidad como contraparte de la biodiversidad. Por esta razón, se han diseñado estrategias para conservar y dar valor a los espacios con recursos geomineros, de las que han surgido los denominados parques geomineros, los cuales se transforman en fuentes valiosas para preservación, conservación y uso de estos espacios, que en la mayoría de los casos aparecen con importantes niveles de degradación. El objetivo de este trabajo es presentar un diagnóstico preliminar para sentar las bases de un parque geominero en una ciudad de Argentina, con fines de conservación y fomento del denominado geoturismo.

Palabras clave: Geoturismo, geodiversidad, parques geomineros, patrimonio minero, Argentina.

\begin{abstract}
In recent decades the mining heritage has become increasingly important from the standpoint of its social value as well as from tourism activities, while the need arose to conserve and protect geodiversity and biodiversity counterpart. For this strategy to preserve and enhance the value spaces geomining resources are designed. Thus arose the so-called geo-mining parks, which are transformed into valuable tools for preservation, conservation and use of these spaces in most cases mate with significant levels of degradation. The aim of this paper is to present a preliminary diagnosis to lay the foundations of a geo-mining park in a city of Argentina for preservation and promotion of the so called geotourism.
\end{abstract}

Keywords: Geotourism, biodiversity, geomining parks, mining heritage, Argentina. 


\section{Introducción}

El patrimonio minero, producto del trabajo del hombre, es considerado hoy uno de los componentes del patrimonio cultural que debe ser conservado y preservado por su valor para la identidad social, así como también por la importancia que está asumiendo en el desarrollo turístico de muchas regiones, iniciado hace unas décadas en Europa y que comienza a expandirse con fuerza por el resto del mundo. Por su parte, el relativamente nuevo concepto de geodiversidad, entendido como contraparte del concepto de biodiversidad, también comienza a ser discutido y analizado en diferentes instancias, y se observa al mismo tiempo su importancia para la preservación de fenómenos y procesos abióticos y sus relaciones con el resto de los factores, así como también su inclusión en actividades de tipo cultural, turístico y recreativo.

En relación con la geodiversidad y la biodiversidad, surge el denominado geoturismo como una modalidad dentro del turismo alternativo que busca esta revalorización del patrimonio geológico y la geodiversidad, al tiempo que se convierte en un instrumento valioso para su conservación.

Esta simbiosis de patrimonio minero, geodiversidad y geoturismo puede plasmarse en los llamados parques geomineros, los cuales son áreas más o menos extensas donde es posible rescatar y poner en valor restos de la actividad minera, de rasgos destacados geológicos y geomorfológicos, etc., contribuyendo así a las posibilidades de un desarrollo local dentro del marco de la sustentabilidad.

Considerando la simbiosis mencionada, el objetivo del presente trabajo es analizar de forma preliminar la potencialidad del área de la ciudad de Tandil, provincia de Buenos Aires, Argentina, para establecer un parque geominero como una forma de revalorización del patrimonio minero local y de la geodiversidad, y como un producto turístico nuevo que brinde mayores posibilidades de desarrollo a la comunidad y mejore la competitividad del destino.

\section{La geodiversidad}

El concepto de geodiversidad surge a finales de la década de 1990, aplicado a la gestión de espacios protegidos, y de alguna manera como contraria y complementaria del término biodiversidad, por ser necesaria la elaboración de un concepto que abarque también los elementos abióticos del medio natural (Serrano Cañadas y Ruiz Flaño, 2007).

La definición de este concepto, relativamente nuevo, no está exenta de ambigüedades, como muchos otros conceptos y definiciones teóricas en distintas ciencias y disciplinas. Es así que muchas conceptualizaciones iniciales consideran la geodiversidad como sinónimo de diversidad geológica, cuestión que todavía puede observarse en mucha de la bibliografía, y de la que derivan no pocos problemas de carácter conceptual, principalmente en el momento de planificar y gestionar áreas protegidas o territorios en general.

Desde una perspectiva simple, la geodiversidad ha sido definida, por ejemplo, por Villalobos (en Volth, 2008, p. 2), como "la variabilidad que es posible encontrar en un determinado territorio en cuanto al número y la calidad de registros geológicos de interés para la ciencia y la educación". Por su parte, Johansson (en Serrano Cañadas y Ruiz Flaño, 2007, p. 82) la define como "la variación de fenómenos y procesos geológicos en un área definida", y Stanley (en Serrano Cañadas y Ruiz Flaño, 2007, p. 82) la considera como la "variedad de ambientes, fenómenos y procesos geológicos" que son "la infraestructura para la vida sobre la tierra". Estas son algunas de las definiciones que de alguna forma están limitando el concepto de geodiversidad en la geología. 
Pero, por otro lado, algunos autores presentan una revisión del concepto de geodiversidad, por ejemplo Nieto $(2001$, p. 7$)$, quien expresa que la geodiversidad es "el número y la variedad de estructuras (sedimentarias, tectónicas, geomorfológicas, hidrogeológicas y petrológicas) y de materiales geológicos (minerales, rocas, fósiles y suelos), que constituyen el sustrato físico natural de una región, sobre las que se asienta la actividad orgánica, incluyendo la antrópica”.

Por su parte, Serrano Cañadas y Ruiz Flaño (2007, p. 82) han elaborado una metodología para su valoración y proponen una definición más integradora, que incluye los diversos elementos del medio físico, y según la cual la geodiversidad se entiende como "la variabilidad de la naturaleza abiótica (...) junto a sistemas generados por procesos naturales, endógenos y exógenos, y antrópicos, que comprende la diversidad de partículas, elementos y lugares".

Otra de las definiciones, también integradora, fue planteada por Kozlowski (en Serrano Cañadas y Ruiz Flaño, 2007, p. 82), para quien la geodiversidad es la "variedad natural en la superficie terrestre, referida a los aspectos geológicos, geomorfológicos, suelos, hidrología, así como otros sistemas generados como resultado de procesos naturales (endógenos y exógenos) y la actividad humana".

La Junta de Andalucía (2008, p. 11) define la geodiversidad como la "variedad de rasgos y procesos geológicos (rocas, minerales y fósiles), geomorfológicos (paisajes, formas del terreno y procesos físicos), edáficos e hidrogeológicos, incluyendo sus relaciones, propiedades y sistemas de un determinado territorio".

Sintéticamente, siguiendo a Serrano Cañadas y Ruiz Flaño (2007), puede considerarse que los elementos que componen la geodiversidad sobre la superficie terrestre son: a) la topografía (energía, rugosidad);

b) la geología (materiales minerales, litología, depósitos superficiales, fósiles, tectónica, estructuras);

c) la geomorfología (morfoestructuras, sistemas morfogenéticos, procesos, formas de erosión, formas de acumulación, microformas);

d) la hidrología (estados del agua, agua líquida, nieve, hielo, elementos hidrológicos, ríos, fuentes, humedales) y

e) los suelos (órdenes, subórdenes).

De esta forma, la geodiversidad se identifica como "un concepto útil para la gestión y conservación del patrimonio abiótico, cuya incorporación es necesaria en políticas locales de desarrollo sostenible y de valoración de recursos naturales" (Serrano Cañadas y Ruiz Flaño, 2007, p. 84). El análisis integrado de elementos geológicos, geomorfológicos, edafológicos e hidrológicos, con las interacciones entre ellos, contribuye a que la planificación y gestión del territorio tenga mejores resultados. Por esta razón, la geodiversidad incluye todos los componentes del medio físico abiótico, no solo los geológicos.

\section{Breve conceptualización del patrimonio minero}

El patrimonio cultural de un espacio geográfico está constituido por todos aquellos elementos y manifestaciones tangibles o intangibles producidos por la sociedad, resultado de un proceso histórico en el que la reproducción de las ideas y del material se constituye en un factor que identifica y diferencia a ese país o región de otros.

El patrimonio, relacionado con la herencia, es un concepto que alude a la historia, se en- 
laza con la esencia misma de la cultura y es asumido directamente por los grupos locales. Ello implica un proceso de reconocimiento intergeneracional de unos elementos (desde el territorio a la ruina) como parte del bagaje cultural, y su vinculación a un sentimiento de grupo (Santana, 2003).

El patrimonio, por lo tanto, es el producto de un proceso histórico, dinámico, una categoría que se va conformando a partir de la interacción de distintos actores sociales y de diferentes situaciones, que obligan a realizar una mirada a largo plazo, tanto en la concepción como en el uso de los recursos.

De esta forma, el patrimonio minero se inscribe dentro del patrimonio cultural y puede ser definido como el conjunto de labores mineras realizadas en explotaciones a cielo abierto o subterráneas, estructuras inmuebles y muebles, así como instalaciones periféricas, de transporte, documentos, objetos y elementos inmateriales (formas de trabajo), vinculados con actividades mineras del pasado o actuales, a los que un grupo social reconoce valores históricos, culturales o sociales.

Este reconocimiento en ocasiones es minimizado o relativizado, producto de la imagen negativa que tiene la actividad minera por su accionar, entendido como destructivo y alterador del paisaje.

Aparte de su innegable vínculo con el patrimonio geológico -puesto que las explotaciones mineras se desarrollan sobre los yacimientos minerales y las rocas-, esta definición presenta conexiones tanto con el patrimonio histórico, arqueológico e industrial, como con la historia económica y el desarrollo tecnológico y social de la región. La escala geográfica de la actividad depende del desarrollo de esta última.

El propósito esencial de los estudios de patrimonio minero es localizar y valorar los elementos que por sus características y estado de conservación puedan considerarse como bienes patrimoniales, además de proponer medidas para su conservación y fomentar su interés desde un punto de vista patrimonial -como identidad social-, pero también desde lo turístico y lo recreativo.

El patrimonio minero, como explica Cañizares Ruiz (2011), integra, entonces, el conjunto de restos materiales e inmateriales heredados de las actividades mineras, de manera específica, que se han desarrollado en el pasado o que se desarrollan en la actualidad y que conforman la memoria colectiva de una determinada población. Partiendo de que tiene una vertiente geológica (patrimonio geológico-minero), vinculada a la riqueza del yacimiento, y otra propiamente minera, relacionada con los espacios productivos (cuenca minera) y los sociales (hábitat, servicios, etc.), se le reconocen diferentes valores: el valor histórico como fuente de información de anteriores etapas socioeconómicas; el valor material, que conserva el patrimonio mueble y el inmueble; el valor cultural y sentimental; el valor estético, vinculado generalmente a los componentes artísticos de la arquitectura industrial; el valor emocional, relacionado con la trayectoria vital de los mineros; y el valor tecnológico, que se deriva del proceso extractivo, tanto si se trata de elementos aislados como de conjuntos mineros o de paisajes culturales mineros.

Entonces, podemos decir que dentro de un esquema amplio, el patrimonio minero incluye elementos que hacen a los procesos productivos de extracción y transformación, a las actividades concatenadas que incluyen inmuebles (zonas de producción, de vivienda, etc.), muebles (maquinaria, herramienta, archivos, etc.) y modos de vida de los trabajadores, el know how de los procesos asociados al aprovechamiento de los recursos desde una mirada del sistema. 
Aunque actualmente no existe una metodología general para la identificación y valoración de los elementos constitutivos de un patrimonio minero, lo habitual es seguir el criterio de ponderar los diversos aspectos (mineros, tecnológicos, arqueológicos, históricos, documentales, sociales, paisajísticos, etc.) de los restos de las explotaciones y sus entornos, así como su estado de conservación y su grado de vulnerabilidad frente a distintas acciones, tanto naturales como antrópicas.

En situaciones de abandono reciente de la actividad minera, la valorización del patrimonio minero es una posible alternativa para resolver problemas de tipo socioeconómico, reorientando las áreas mineras abandonadas o en decadencia hacia un uso turístico-recreativo sustentable.

Los ejemplos de aprovechamiento del patrimonio minero son numerosos, por ejemplo, en España (Carcavilla, Durán y López Martínez, 2008), a finales de la década de los ochenta, el inicio del actual Parque Minero de Riotinto, el cual nació como museo y paulatinamente fue incorporando nuevas actividades, con recorridos por la corta Atalaya, el barrio inglés de Bellavista o el ferrocarril turístico; a este espacio se agregan lugares como el Parc Cultural de la Muntanya de Sal, en Cardona (Barcelona) y el Museo de la Minería y la Industria en El Entrego (Asturias), inaugurados en 1994. Algunos años más tarde aparecieron el Museo de las Minas de Cercs (Barcelona) y el Centro de Interpretación de la Minería en Barruelo de Santullán (Palencia). Posteriormente se sumaron sitios como Gallarta (Vizcaya), Escucha (Teruel), Andorra (Teruel), La Unión (Murcia), Puertollano (Ciudad Real), Sabero (León) y el Parque Minero de Almadén en Ciudad Real.

En Latinoamérica, los ejemplos son mucho más reducidos por distintas razones, por ejemplo, el hecho de que la actividad minera sigue en crecimiento en algunos lugares, a diferencia del caso europeo, como es el caso del yacimiento de hierro de Sierra Grande en Argentina, que había iniciado la actividad turística con el cierre y que debió cancelarse por la reapertura de la mina con capital chino. Otras razones son la falta de un mercado interno proclive a este tipo de producto, la falta de interés del sector privado y público, etc.

De todas formas, existen ciertos casos y algunas propuestas en ese sentido, por ejemplo, en la Mina de Aguas Claras y en el Parque de Inhotim de Minas Gerais, ambos ubicados en Brasil; y en Chile se destacan los proyectos de revalorización de Humberstone y de Lota, el primero en el desierto de Atacama y el segundo en Concepción. En Argentina nacieron algunos emprendimientos, como la Mina La Carolina en las Sierras de San Luis, la Mina La Mejicana en La Rioja y las Minas de Wanda, de piedras preciosas y semipreciosas, en la provincia de Misiones. Estos y algunos otros ejemplos en Colombia, Uruguay, Bolivia o Perú muestran un crecimiento, aunque lento en ocasiones, del aprovechamiento del patrimonio minero con fines culturales y turísticos.

\section{Geoturismo: una modalidad del turismo alternativo}

Dado el crecimiento acelerado del turismo de masas o convencional desde la década de los setenta y las transformaciones espaciales significativas que generó, las reflexiones en torno a sus efectos económicos, sociales y naturales negativos aumentan. En el mismo sentido, se gestan cambios en las dinámicas productivas en general y en la actividad, así como también en las propias motivaciones de viajes; incluso se genera una creciente sensibilización de la sociedad en cuanto al nivel de conciencia sobre los efectos que el consumo del producto turístico causa, aunque sea un servicio. Es en dicho contexto donde se observa el surgimiento de nuevas 
modalidades y productos de turismo, para segmentos más específicos, con estrategias de comercialización y de generación de servicios flexibles, nuevos roles de los turistas, procesos de intervención de las comunidades residentes activas, escenarios novedosos atractivos y más ricos por su autenticidad y su propio valor patrimonial en diferentes escalas.

Sin que sea la intención discutir y reflexionar sobre este proceso, podemos decir que segmentos específicos, como el ecoturismo, el turismo aventura y el turismo rural fueron apareciendo. A estos se sumaron, en la literatura turística, infinidad de acepciones, como enoturismo, turismo gastronómico, turismo indígena, turismo industrial, etc. Desprendido de estas nuevas tipologías, uno de los más nuevos conceptos que surgieron para identificar un segmento de interés particular es el denominado geoturismo. El primero en conceptualizarlo fue Hose (1995, p. 3), quien considera a este segmento como "los servicios de interpretación y las instalaciones con el fin de permitir a los turistas adquirir el conocimiento y la comprensión de sitios geológicos y geomorfológicos en lugar de un simple examen de la estética". Hose (1997, p. 2956), en una revisión conceptual propia, añade la necesidad de garantizar, por medio del geoturismo, la conservación de los sitios geológicos o geomorfológicos, ya que evidentemente estos últimos se transforman en los georecursos que, puestos en valor, servirán para el desarrollo de la actividad turística.

De acuerdo con Geremia (INE, 2004, p. 12), el geoturismo es definido como "una actividad recreativa con fines culturales y educativos en donde los principales sujetos o atracciones son la geología y la geomorfología de los paisajes; estos lugares son sujetos de visitas y recorridos, como por ejemplo, las excursiones a cavernas, montañismo, alpinismo, observación de la dinámica de playas y todas las actividades relacionadas y que motiven la educación geo-científica, estimulando al mismo tiempo la economía de dichos sitios".

Por su parte, Ruchkys (en Manosso, 2012) define esta modalidad turística como aquel segmento "que tiene al patrimonio geológico como su principal atractivo y busca su protección por medio de la conservación de sus recursos y de la sensibilización del turismo, utilizando para esto la interpretación de este patrimonio, tornándolo accesible al público, además de promover su difusión y el desarrollo de las ciencias de la tierra".

Durante el Congreso Internacional de Geoturismo (National Geographic Society, 2011), fue presentada la denominada Declaración de Arouca, en la que se reconoce la necesidad de aclarar el concepto de geoturismo, el cual fue definido como el "turismo que sustenta e incrementa la identidad de un territorio, considerando su geología, ambiente, cultura, valores estéticos, patrimonio y bienestar de sus residentes. El turismo geológico se asume como uno de los diversos componentes del geoturismo".

De esta forma, este segmento es entendido como otra modalidad de turismo que, buscando el contacto con la naturaleza, trata de explorar la variedad de elementos del medio físico -tales como formaciones de rocas, fósiles, accidentes geográficos, etc.-, es decir, la geodiversidad, dentro de un esquema de desarrollo sustentable, donde prestadores de servicios y turistas comprenden y se comprometen con la preservación y conservación de estos sitios con valor desde el punto geológico y minero.

Así, el geoturismo es el segmento que utiliza la geodiversidad como recurso turístico y dispone de los ambientes geológicos, geomorfológicos y paleontológicos dotados de una cualidad estética o no -tales como cuevas, formaciones rocosas, afloramientos rocosos, características de la superficie, cadena de 
montañas, entre otros-, para el desarrollo de la actividad, siendo esta la fuente de motivación de los turistas.

También, desde la definición de la National Geography Society (2011), este tipo de turismo intenta integrar y valorizar a las comunidades locales, la diversidad cultural y la conservación de los recursos naturales, además de su estética y sus otras características geográficas dirigidas a minimizar los impactos a fin de constituir un turismo alternativo.

Por otro lado, Newsome \& Dowling (en Manosso, 2012, p. 322) señalan que "los elementos abióticos, como las rocas y el suelo, por ejemplo, no despiertan el mismo interés de las personas en comparación con los elementos bióticos, tales como plantas y animales, que representan la vida dotada de color, sonidos e interacciones. Sin embargo, significa que independientemente de la estética de los elementos abióticos, sus significados geocientíficos pueden representar un importante potencial para el uso turístico".

Los lugares de interés y atracciones de geoturismo, conocidos en la mayoría de los casos como geositios e incluso como geomorfositios, se asocian a los valores de la geodiversidad que no siempre es estética o atractiva, o que en ocasiones se encuentra en lugares de difícil accesibilidad física o legal, inclusive, porque la geodiversidad y la biodiversidad están presentes en todas las superficies, con diferentes variedades, entre los elementos. Por lo tanto, la geodiversidad y la biodiversidad son comunes en algunos sitios y están presentes incluso en las zonas urbanas, tales como canteras, construcciones, calles, parques, etc. Esto implica la necesidad de presentar ambos conceptos de una forma amena y atractiva para el visitante, siendo en este caso sumamente importante la aplicación de técnicas provistas desde la interpretación del patrimonio.

\section{Definición, características y valor de los parques geomineros}

La actividad minera produce importantes transformaciones en el espacio, algunas de ellas muy cuestionadas en la actualidad, y otras de valor histórico e incluso natural, que constituyen un acervo que podría considerarse patrimonio minero. Este puede estar compuesto por múltiples presentaciones, como ya fue explicado, por galerías, pozos, fábricas, lavaderos, maquinaria diversa, ferrocarriles, funiculares, explotaciones a cielo abierto, escombreras, afloramientos minerales y muchos otros elementos relacionados con la actividad minera.Además, por las características de extracción, la actividad permite visibilizar más fácilmente formaciones y estructuras geológicas que se combinan en recursos geomineros.

Cabe destacar aquí que este artículo no desconoce los debates que desde hace décadas se dan sobre el agotamiento del paradigma extractivo, la necesidad de repensar la sobreexplotación de los recursos no renovables, los daños al paisaje y la contaminación, que actualmente se vincula con la actividad minera, en particular la megaminería. Por el contrario, intenta poner la mirada en los patrimonios de una actividad extractiva centenaria que requiere ser revisada a partir de su significado para la identidad de algunas comunidades, en la evolución histórica de algunas regiones y en la actual situación de crisis y abandono de estos espacios, con sus implicancias negativas, dado que el declive de la actividad minera se traduce en el cierre de numerosas explotaciones y, con ello, en el deterioro de este importante patrimonio minero, que se va perdiendo lentamente, y de las repercusiones en las comunidades asociadas.

Los restos de la actividad minera devienen con el paso del tiempo en ruinas. De instalaciones y edificios en ocasiones solo quedan las paredes, ya que todo lo que podría tener algún valor es desmantelado a veces por las 
mismas empresas, pero en innumerables casos por la población cercana, que se aprovecha de la falta de seguridad de estos espacios.

De esta forma, tanto las explotaciones a cielo abierto que se convierten en enormes "huecos" o cuerpos de agua (por las vertientes), como las subterráneas que tienen las bocas tapadas por vegetación, basuras, etc., o cuyas galerías son objeto de uso espontáneo, se transforman en sitios de riesgo, proclives a accidentes, derrumbes, etc.

En tal sentido, es clave pensar estos espacios desde el hoy, con un sentido no solo de restauración ambiental, remediación o mitigación, sino también desde sus oportunidades. Considerando esta problemática, una alternativa para evitar la degradación y pérdida de este patrimonio geológico-minero puede ser la creación de parques geomineros. Estos pueden permitir la conservación del patrimonio geológicominero y minimizar o evitar la degradación del medio natural, cumpliendo al mismo tiempo con una labor educativa y recreativa al mostrar y hacer reflexionar a la sociedad sobre una actividad que ha sido y es muy importante como suministradora de materias primas necesarias para nuestra forma y calidad de vida, pero que al mismo tiempo es presentada como una actividad sumamente depredadora del medio. Además, es posible aprender sobre los yacimientos minerales y los aspectos geológicos que están relacionados a ellos.

Al respecto, Orche (2003, p. 2) define los parques geomineros "como áreas mineras, continuas espacialmente o no, en las que se protege el patrimonio geológico y minero ubicado en ellas, acondicionándolas para que puedan ser visitadas por el público interesado, con un objetivo lúdico, didáctico o de investigación. También se pueden considerar como tales las reproducciones a escala natural de labores mineras, en su ambiente geológico, o instalaciones asociadas en las que se muestran los procesos mineros o na- turales. Por tanto, no estarían incluidos los museos puramente geológicos, sin conexión con labores de explotación".

Los parques geomineros, de esta manera, se convierten en atractivos turísticos y recreativos capaces de generar empleo e ingresos, evitando la degradación social que en muchas ocasiones se produce al cerrar las explotaciones mineras, e incluso, si las condiciones geológico-mineras lo permiten, en centros de investigación mineralógica, petrográfica, mineralogénica, etc.

Para la creación de un parque geominero, evidentemente es necesario seleccionar las áreas mejor conservadas desde el punto de vista de su patrimonio minero y las más representativas desde el punto de vista geológico; para ello se requiere establecer parámetros y variables para utilizar en grillas que permitan la mejorar valoración de los sitios, evitando de esa forma la incorporación de elementos con escaso valor.

Considerando esto, y siguiendo en parte lo expresado por Orche (2003), las funciones que un parque geominero puede cumplir son amplias y variadas, siendo las siguientes las principales actividades que se pueden programar:

a) Actividades turístico-recreativas, aquellas vinculadas directamente al esparcimiento y entretenimiento de quien visita el parque. Están orientadas a turistas o a la población local que desea realizar actividades recreativas. Por ejemplo, visita guiada por un sendero, que implica el desarrollo de una actividad deportiva no competitiva con el agregado del conocimiento de algunas características geológicas, geomorfológicas, etc. del sector recorrido.

b) Actividades culturales, aquellas en las cuales la estructura del parque permite el 
desarrollo de actividades de tipo cultural, vinculadas a la actividad minera o procesos geológicos. Por ejemplo, es posible utilizar áreas de antiguas explotaciones mineras para espectáculos artísticos, siendo en este caso el espacio solo un soporte básicamente, pero estableciendo de esta forma un vínculo con la sociedad, al menos mediante el uso, eliminando la percepción social de que son solo áreas abandonadas y peligrosas.

c) Actividades pedagógicas, aquellas que pueden estar organizadas desde el sector educativo formal, informal o no formal, pero que cuentan con alguna planificación previa e incluso con actividades realizadas antes de visitar el lugar, de manera que pueden aplicarse tanto en los niveles educativos básicos y medios como en el nivel superior universitario o terciario. Este tipo de actividades permiten encontrar relaciones con un amplio abanico de carreras (desde geología, geografía, arquitectura, antropología, ingeniería, turismo, hasta cine, fotografía, etc.).

d) Actividades científicas, aquellas que pueden tener lugar cuando el parque geominero incluye elementos de valor científico, típicamente minerales. Estas actividades pueden ser objeto de protección especial, de modo que se preserven para su estudio por especialistas, de manera que la participación del público en general puede ser reducida o estar vedada.

Desde un punto de vista territorial, un parque geominero se puede componer de cinco grandes áreas:

- Las explotaciones subterráneas y/o a cielo abierto. La actividad recomendable es la visita guiada o incluso en ocasiones autoguiada. Estas actividades muestran las características de la explotación, el proceso de extracción del mineral y el funcionamiento de la propia explotación en sí, y se pueden simular una o varias operaciones mineras. En este caso, se mantendrán todas las señales propias de la mina para el embarque y desembarque de las personas. El recorrido puede realizarse utilizando los medios de transporte mineros, por ejemplo, ferrocarriles, vagonetas mineras reacondicionadas, etc. De ser posible, se mostrarán las mineralizaciones explotables, reales o simuladas.

- Las construcciones e instalaciones mineras inmuebles (edificios de oficinas, galpones, etc.). Los edificios propios de la actividad minera (oficinas, talleres, almacenes, dirección, etc.) son un marco muy adecuado para montar actividades de todo tipo e implantar los servicios de uso general para los visitantes. En ellos pueden instalarse museos o salas de exposiciones temáticas, por ejemplo, con relación a la historia de la minería, impactos de la minería positivos y negativos de la zona, exposiciones de arte (esculturas en piedra, pintura, etc.), talleres de aprendizaje de diverso tipo (identificación de minerales, tallado de piedra, etc.), incluso tiendas de objetos relacionados con el parque o servicios gastronómicos.

- Las maquinarias y equipamientos muebles que quedaron dispersos por el territorio. En el espacio minero queda un cierto número de maquinarias y equipos, en ocasiones difíciles de mover y de depositar en algún lugar, que pueden servir para distintos propósitos, por ejemplo, para crear un museo de equipos mineros de gran tamaño, o zonas de exhibición de funcionamiento de equipos mineros, mediante originales o réplicas a escala. También pueden permitir la creación de parques de juegos para niños y áreas para la práctica de actividades recreativas como escalada, rappel, tirolesa, etc. 
- Viviendas o barrios de los mineros. Esta área comprende los edificios que fueron dedicados a viviendas de los mineros y sus familias. Este tipo de construcciones suele ser de gran interés, pues constituye conjuntos con un estilo arquitectónico propio y característico de la época. $\mathrm{Su}$ uso como albergue de visitantes es una opción que no debe desdeñarse.

- El territorio minero y su geodiversidad. Es el espacio abierto que incluye varias explotaciones mineras, en el que pueden establecerse recorridos a pie, a caballo, en ferrocarril o con vehículos todo terreno, para mostrar las peculiaridades geológicomineras del lugar. Pueden establecerse rutas, senderos, circuitos, etc., de distinta longitud y dificultad, para visitar estructuras geológicas, afloramientos minerales, explotaciones a cielo abierto, construcciones mineras y urbanismo asociado, escombreras con minerales y fósiles, etc.

\section{Metodología}

La metodología aplicada es de tipo exploratoria-descriptiva y se basa en la adaptación de los pasos enunciados en la propuesta metodológica de Rendón Rivera, Henao Arroyave y Osorio Cachaya (2013), a saber:

1. Delimitación del área geográfica y administrativa: sector urbano y periurbano de la ciudad de Tandil.

2. Recopilación bibliográfica para elaborar el estado de situación actual del patrimonio minero y la geodiversidad. (No presentado en detalle en este artículo).

3. Identificación de sitios y áreas de interés con su ubicación.

4. Descripciones de los elementos más relevantes de los sitios.
5. Análisis de variables de Valoración de Áreas: valor científico (vc), diversidad (D), valor didáctico (vd) y valor estético (ve). Estas variables fueron aplicadas en el IPMG (Índice de Patrimonio Minero y Geodiversidad).

$$
\begin{gathered}
\text { IPMG: 0,4 vc }+0,2 D+0,2 v d \\
+0,1 v e
\end{gathered}
$$

Los atributos medidos con escala Likert (1 a 5) para su cálculo son:

- Valor científico (vc): de muy importante a irrelevante, de acuerdo con la información que aporta al conocimiento general de la temática.

- Diversidad (D): de único a común, según abundancia, rareza y originalidad o su rol de modelo.

- Valor didáctico (vd): su utilidad como modelo para mostrar procesos.

- Valor estético (ve): su forma, textura y contraste morfológico en relación con su entorno.

La escala Likert de valoración resulta así:

- Menor o igual a 1,5: sin valor como patrimonio.

- De 1,6 a 2,5: bajo.

- De 2,6 a 3,5: valor medio.

- De 3,5 a 5: alto valor.

6. Construcción del Índice de Uso Potencial a partir de las siguientes variables: acceso (Acc), reconocimiento de la comunidad $(\mathrm{Rc})$, relación con otros elementos ambientales (Rea), uso actual (Up), potencial educativo $(\mathrm{Pe})$ y potencial turístico $(\mathrm{Pt})$.

Rev. Turismo y Sociedad, vol. xVII, julio-diciembre 2015, pp. 17-37 
Estas variables fueron aplicadas en el Índice de UP (Índice de Uso Potencial)

$$
\begin{gathered}
\text { IUP: } 0,3 \mathrm{Acc}+0,2 \mathrm{Rc}+0,2 \mathrm{Rea} \\
\quad+0,1 \mathrm{Up}+0,1 \mathrm{Pe}+0,1 \mathrm{Pt}
\end{gathered}
$$

También fueron tabuladas en escala Likert (1 a 5):

- Acceso (Acc): medida en la distancia (directa, 1 km y más de 3 ).

- Reconocimiento de la comunidad (Rc): reconocimiento de la existencia (de mucho a desconocido).

- Relación con otros elementos ambientales (Rea) alta a baja: vínculo con otros aspectos del áreas, complementariedad.

- Uso actual (Up): acorde, parcial, sin uso, incompatible.

- Potencial educativo (Pe): alto a bajo.

- Potencial turístico (Pt) alto a bajo.

La escala Likert de valoración resulta así:

- Menor o igual a 1,5: sin valor de uso potencial.

- De 1,6 a 3: bajo uso potencial.

- $\quad$ De 3,1 a 4,5: valor medio.

- Más de 4,6

7. Variables del Índice de Aptitud: problemas de orden público (POT), tipo de propiedad (Tp), legislación (L), deterioro (D), conocimiento científico sobre esa área $(\mathrm{Cc})$ y amenazas $(\mathrm{A})$.

$$
\begin{gathered}
\text { IAP: 0,3 Pot }+0,2 \mathrm{Tp}+0,2 \mathrm{~L}+0,1 \\
E d+0,1 \mathrm{Cc}+1+0,1 \mathrm{~A}
\end{gathered}
$$

También tabuladas en escala Likert (1 a 5 inversa).

- Problemas de orden público (POT): disturbios, vandalismo, inseguridad.

- Tipo de propiedad (Tp): pública, privada, mixta, siendo la pública la categoría de mayor valoración.

- Legislación (L): grado de protección.

- Deterioro (D): estado de conservación.

- Conocimiento científico sobre esa área $(\mathrm{Cc})$ : cantidad de estudios sobre el área.

- Amenazas (A): presencia o ausencia de amenazas y el carácter natural o antrópico, siendo este último el más valorado.

La escala de valoración resulta así:

- Menor o igual a 2: sin amenazas aparentes.

- De 2,1 a 4: con alguna amenaza.

- Más de 4: con varias amenazas evidenciadas.

El resultado de los tres índices permite clarificar una jerarquía primaria de sitios (JPS) que queda comprendida en la siguiente fórmula:

$$
J P S=I P G M+I U P-I A P
$$

\section{Análisis preliminar para el desarrollo de un parque geominero en Tandil (Argentina)}

\section{Geología y minería}

La ciudad de Tandil se localiza en el sureste de la provincia de Buenos Aires, a $350 \mathrm{~km}$ 
de la ciudad de Buenos Aires (Argentina); su población actual ronda los 123000 habitantes (Instituto Nacional de Estadística y Censos, 2012).

El Partido de Tandil está emplazado en la pampa húmeda, más precisamente en el sistema serrano de Tandilia, que lo atraviesa en sentido NO-SE.
Este sistema orográfico se caracteriza por un conjunto de serranías bajas y de formas redondeadas en el centro y norte del partido, mientras que cambian a formas de mesas o tabulares hacia el oeste y el sur. Con respecto al emplazamiento, la ciudad se extiende de forma irregular en una superficie aproximada de $50 \mathrm{~km}^{2}$ y cuyo soporte se caracteriza por ser una encrucijada de valles que descienden

Figura 1. Ubicación del área de estudio

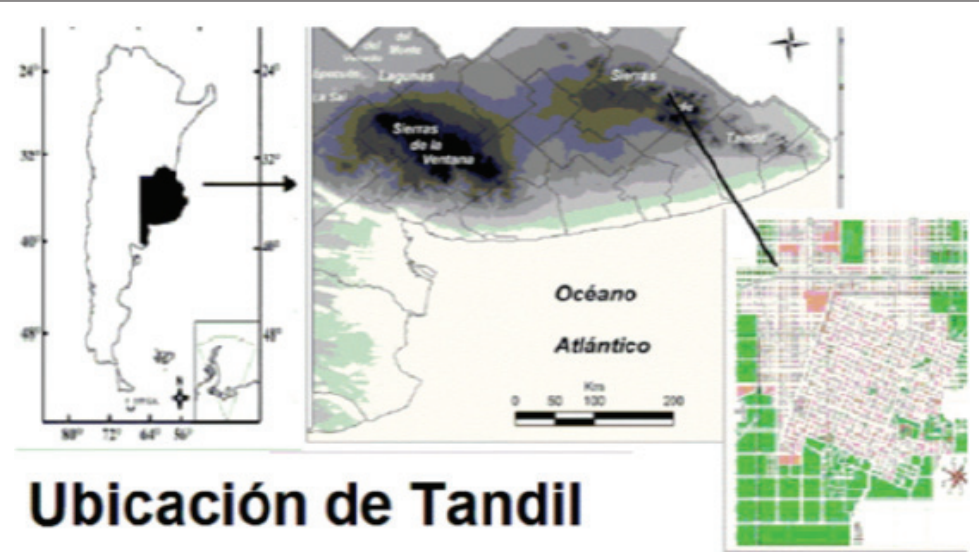

Fuente: Elaboracion propia.

Figura 2. Geología del sistema de Tandilia

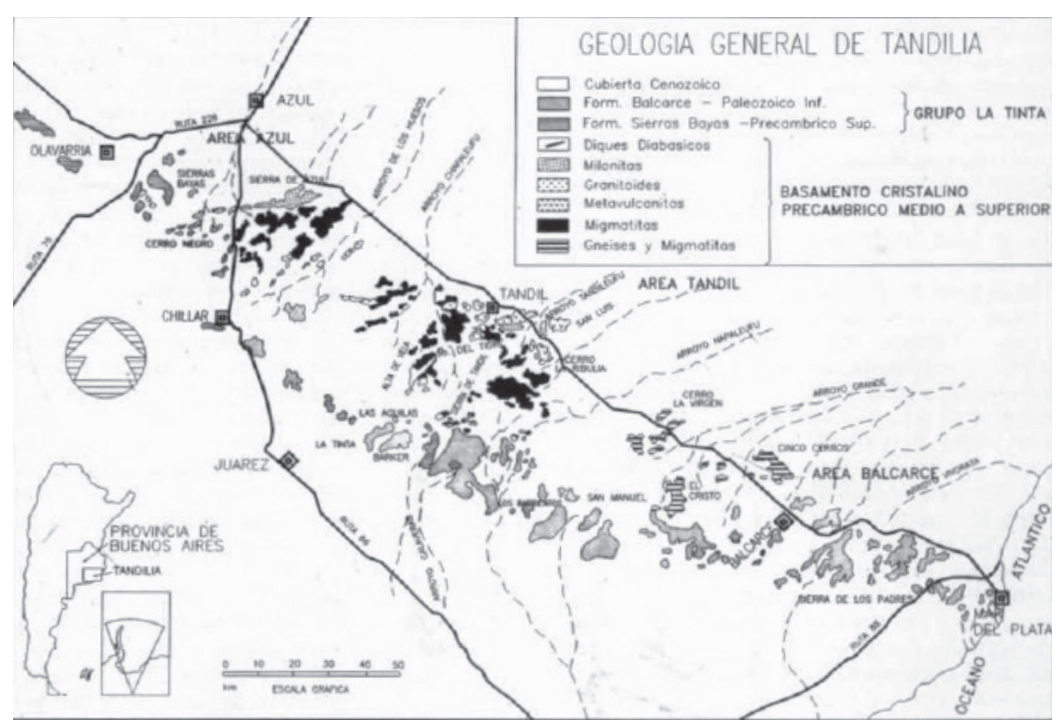

Fuente: Ciclo transamazónico del cratón del Río de La Plata. Recuperado de http://goo.gl/n4qrSP. 
desde las sierras de Tandil hacia la llanura norte y continúa hasta la depresión del río Salado. La ciudad de Tandil está en una zona de interfluvio formada por una lomada al pie y al norte del cerro Independencia, cuya altura es relativamente baja (286 $\mathrm{msnm})$.

Desde el punto de vista geológico, el basamento cristalino precámbrico está expuesto principalmente en las zonas central y septentrional del sistema, formando la mayor parte de las sierras de Tandil y Azul. Se trata de un complejo ígneo-metamórfico que forma parte del cratón del Río de la Plata, que se extiende desde el suroeste de Uruguay, a través de la isla Martín García, hasta las sierras de Tandilia. Este complejo ígneo-metamórfico, o Complejo Buenos Aires, constituye el basamento local al que pertenecen las sierras de la zona de Tandil, con alturas máximas de 300 msnm. Ubicado en el centro del sistema de Tandilia, el conjunto de serranías próximas a Tandil constituye el afloramiento de mayor antiguiedad, entre 2200 y 1800 millones de años (Teruggi \& Kilmurray, 1980).

Estas características geológicas fueron las que permitieron que la explotación minera en Tandil haya sido una de las primeras actividades económicas desarrolladas. La mayoría de ellas fueron localizándose principalmente en el área periurbana y rural, con una impronta que transformó el territorio de forma continua desde fines del siglo XIX hasta la actualidad, siendo relegada a zonas cada vez más periféricas como producto del surgimiento de un movimiento social ambientalista que tiene como objetivo la eliminación de actividades mineras y constructivas en el sector serrano más o menos próximo a la ciudad.

Figura 3. Áreas que concentran sitios para conformar el parque geominero

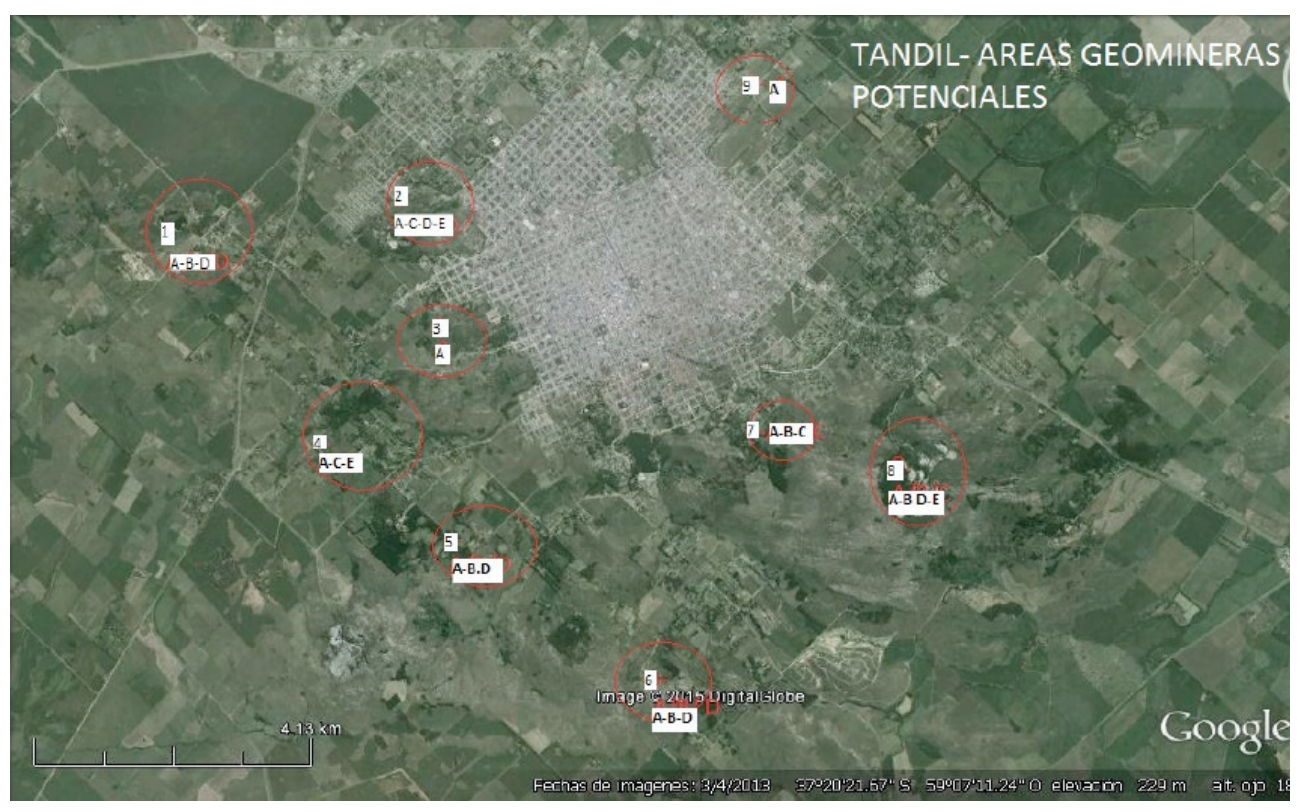

Fuente: Elaboración propia con base en Google Earth.

Referencias del mapa: 1- Co. DE LOS LEONES- 2- Co. MOVEDIZA- 3-CANTERA LOS NOGALES- 4 Co CENTINELA- PASEO DE LOS PIONEROS5- CANTERA AURORA- 6-RESERVA MUNICIPAL SIERRA DEL TIGRE. 7-CANTERA INTERLEN- 8-CANTERA CARBA- Co. LAS ÁNIMAS/ CASCADA. 9- MINAS DE ARENA.

A- Explotaciones subterráneas y a cielo abierto B- Construcciones e inmuebles mineros. C- Maquinarias y equipamientos muebles. D- Viviendas o barrios mineros. E- Geodiversidad. 


\section{Descripción de los elementos y sitios para conformar el parque geominero de Tandil}

A continuación se presentan algunos de los elementos y sitios relacionados con la geodiversidad y el patrimonio minero de Tandil, que podrían estar conformando el parque geominero, sin que esta sea una lista exhaustiva y final.

En el área serrana aledaña a la ciudad de Tandil, se encuentran cientos de frentes de cantera que van desde unos pocos metros cuadrados a varias hectáreas de extensión y que datan desde la etapa picapedrera (1870 en adelante) hasta la etapa de extracción mecanizada (desde principios del siglo XX). Esta actividad, con periodos intensos de explotación, produjo la existencia de un rico patrimonio minero asociado a áreas de extracción, y también la posibilidad de visualización de algunos fenómenos geológicos, por ejemplo, diaclasamientos.

A lo largo del territorio existen numerosos restos de las construcciones realizadas por el hombre desde los comienzos de la actividad minera hasta la actualidad. En la primera foto de la figura 5, se observan restos de galpones de hace unas décadas; las otras tres fotos de la misma figura presentan restos de construcciones de piedra y pinchotes usados por los picapedreros para cortar la piedra de manualmente.

Como testimonio de la actividad, en numerosas canteras queda maquinaria de diverso tipo (palas, retroexcavadoras, sinfines, etc.) de la que en ocasiones suele ser muy costoso desprenderse o enviarla a algún sitio.

Figura 4. Explotaciones subterráneas y/o a cielo abierto
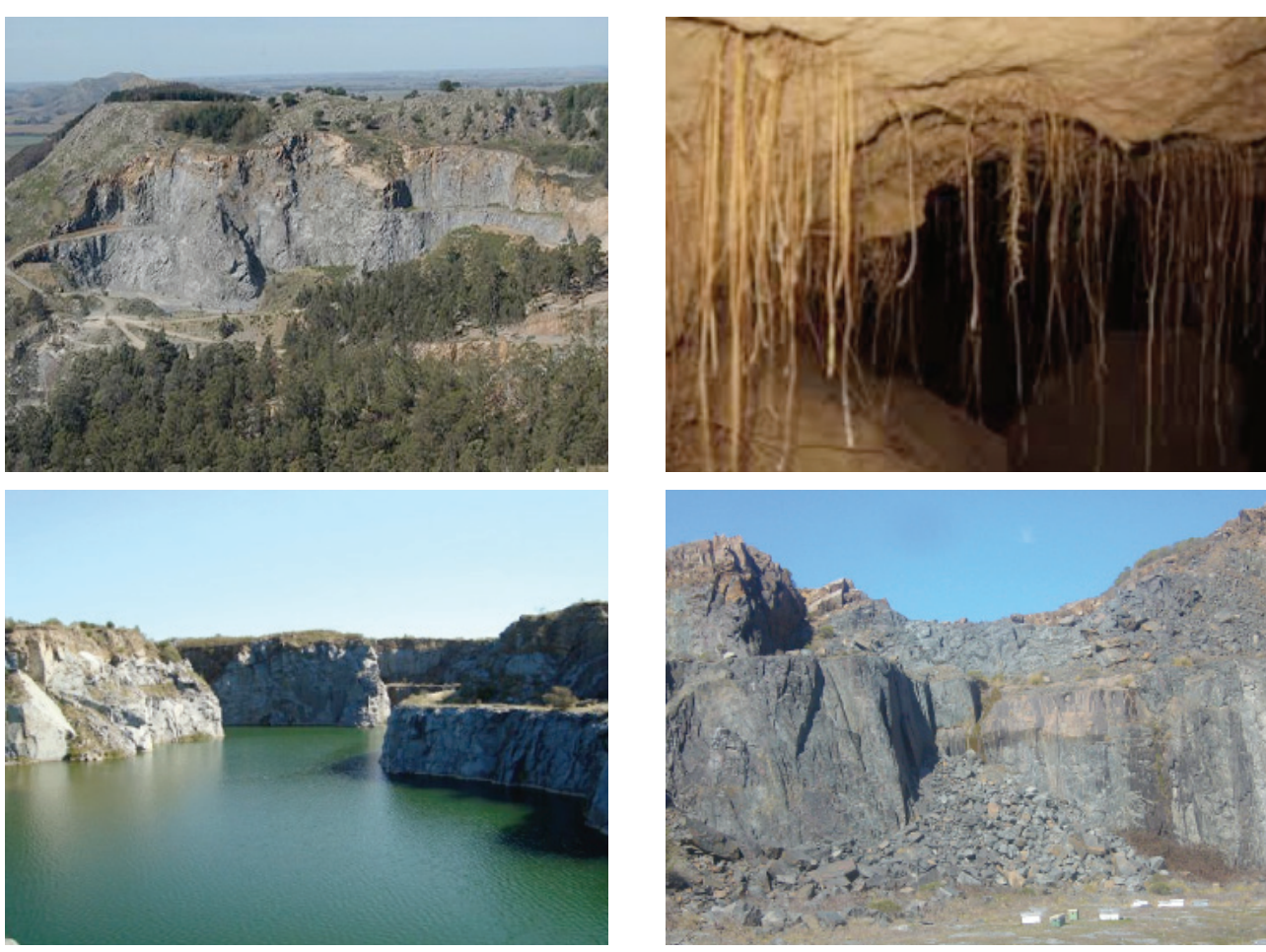

Fuente: Archivo personal, 2014. 
Figura 5. Construcciones e instalaciones mineras inmuebles
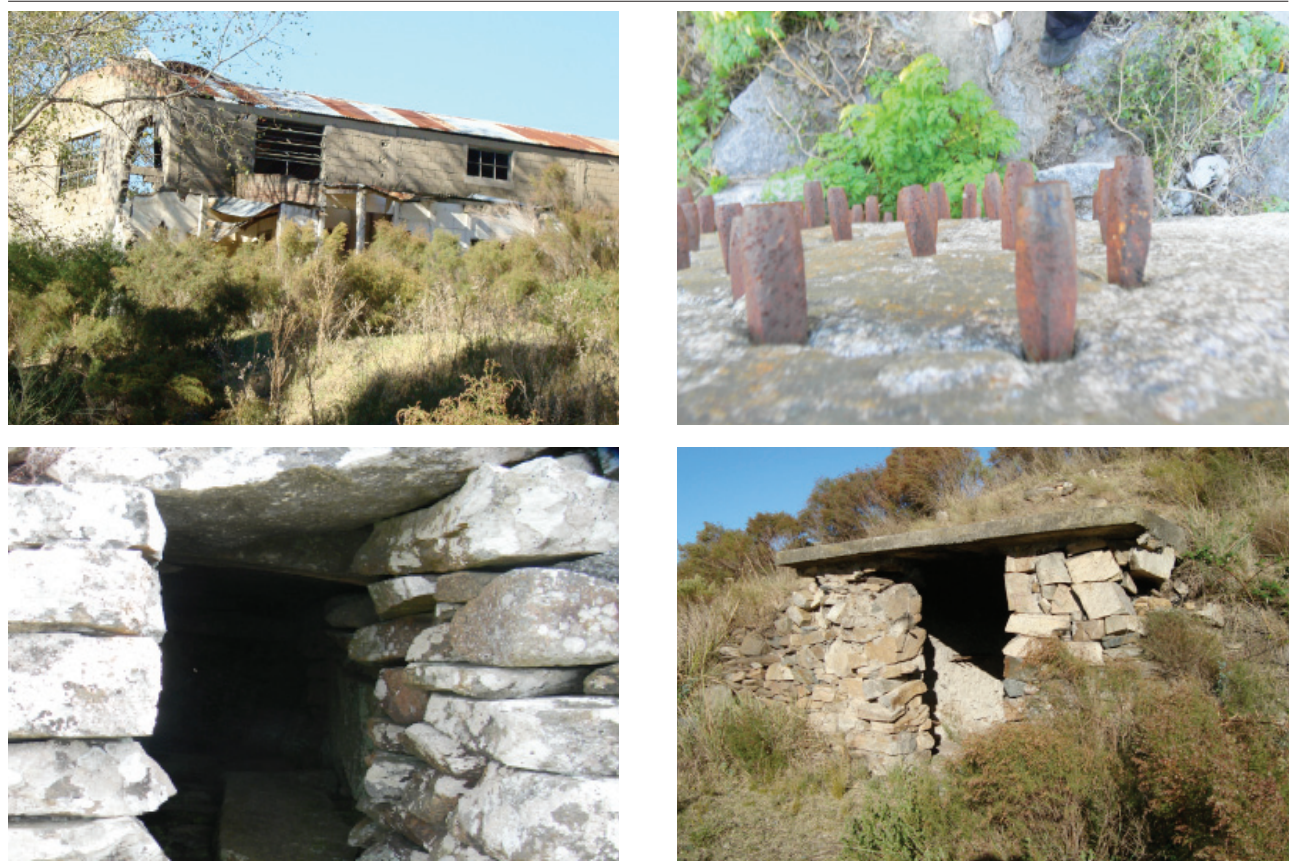

Fuente: Archivo personal, 2014.

Figura 6. Maquinarias y equipamientos muebles
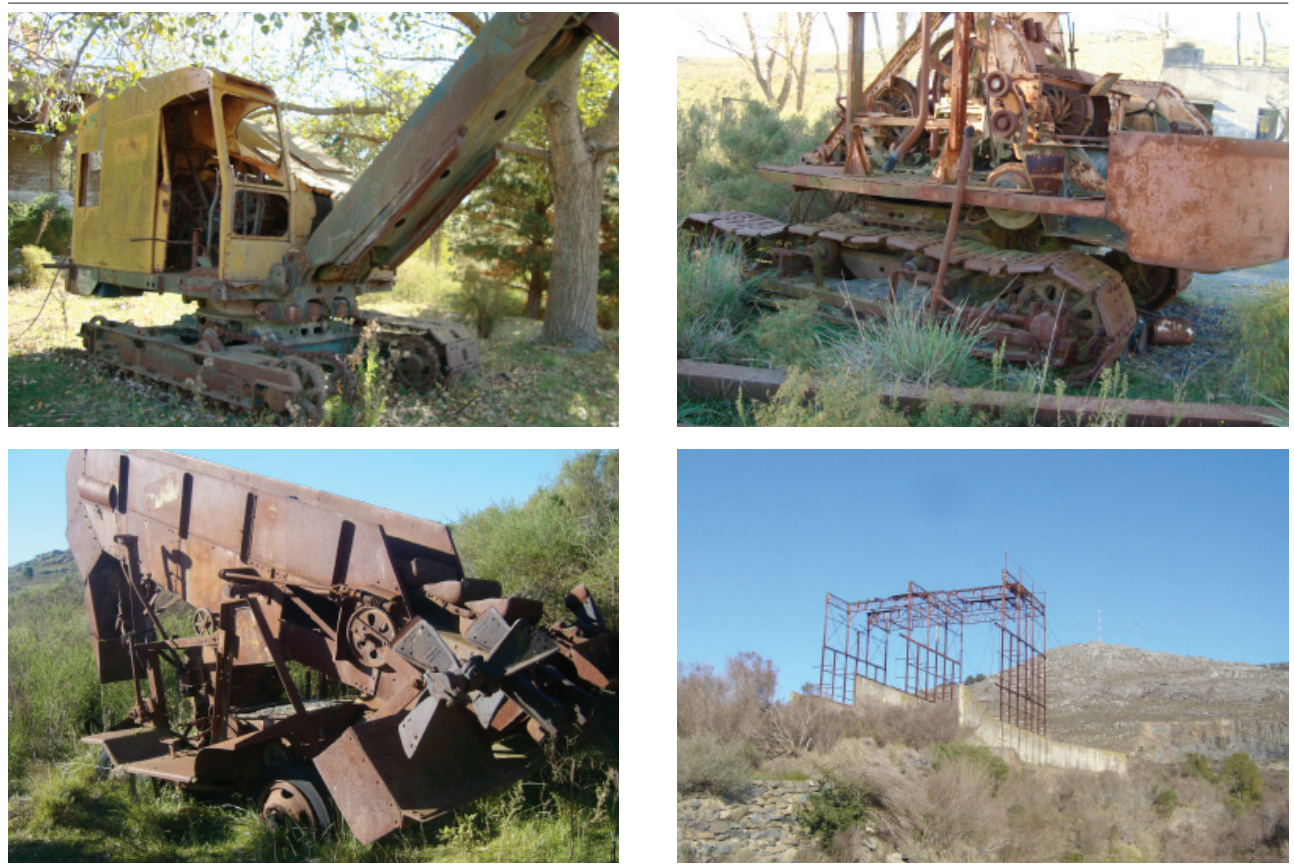

Fuente: Archivo personal, 2014.

Rev. Turismo y Sociedad, vol. XVII, julio-diciembre 2015, pp. 17-37 
Si bien la actividad minera se mezcló con el desarrollo urbano, existió un asentamiento que surgió específicamente con la minería (cerro Leones), donde aún puede observarse, por ejemplo, el bar usado como punto de reunión por los trabajadores de las canteras de la zona.

Desde el punto de vista geológico, Tandilia se caracteriza por su gran antigüedad (alrededor de 2000 millones de años), larga historia geológica, diversidad de rocas ígneo-metamórficas, sus estructuras y por una cubierta precámbrica-eopaleozoica, con un basamento cristalino expuesto que es considerado como una pieza clave para resolver problemas geotectónicos y paleogeográficos del Proterozoico más temprano, conectados a la evolución tectónica del planeta previa a la de Gondwana (Dalla Salda, Spalletti, Poiré, De Barrio, Echeveste y Benilgo, 2006).

El área se caracteriza desde la fisiografía por el basamento granítico; las sierras y los cerros presentan formas redondeadas, que han sido comparadas con cúpulas, domos y conos (Iñiguez, Del Valle, Poiré, Spalletti y Zalba, 1989). Por el contrario, si el relieve ha sido elaborado en cuarcitas, se hace de tipo tabular, y las formas predominantes son mesas y buttes. Los relieves tabulares suelen estar caracterizados por un cinturón de derrubio cuaternario, acumulado al pie de las laderas empinadas.

Estratigráficamente, Tandilia consta de un zócalo de basamento cristalino de edad precámbrica y una cubierta sedimentaria de

Figura 7. Viviendas o barrios de los mineros
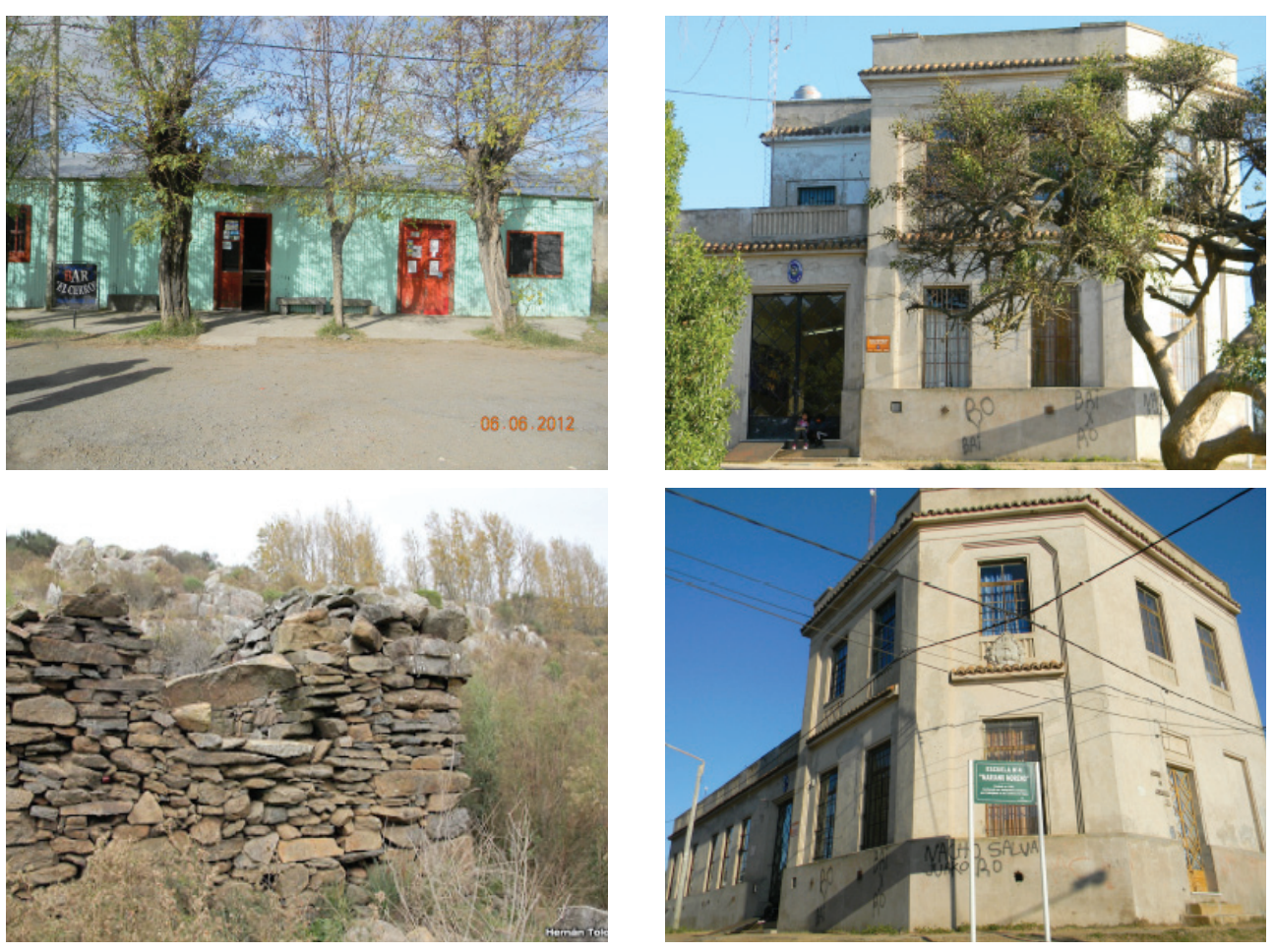

Fuente: Archivo personal, 2012. 
Figura 8. El territorio minero y su geodiversidad
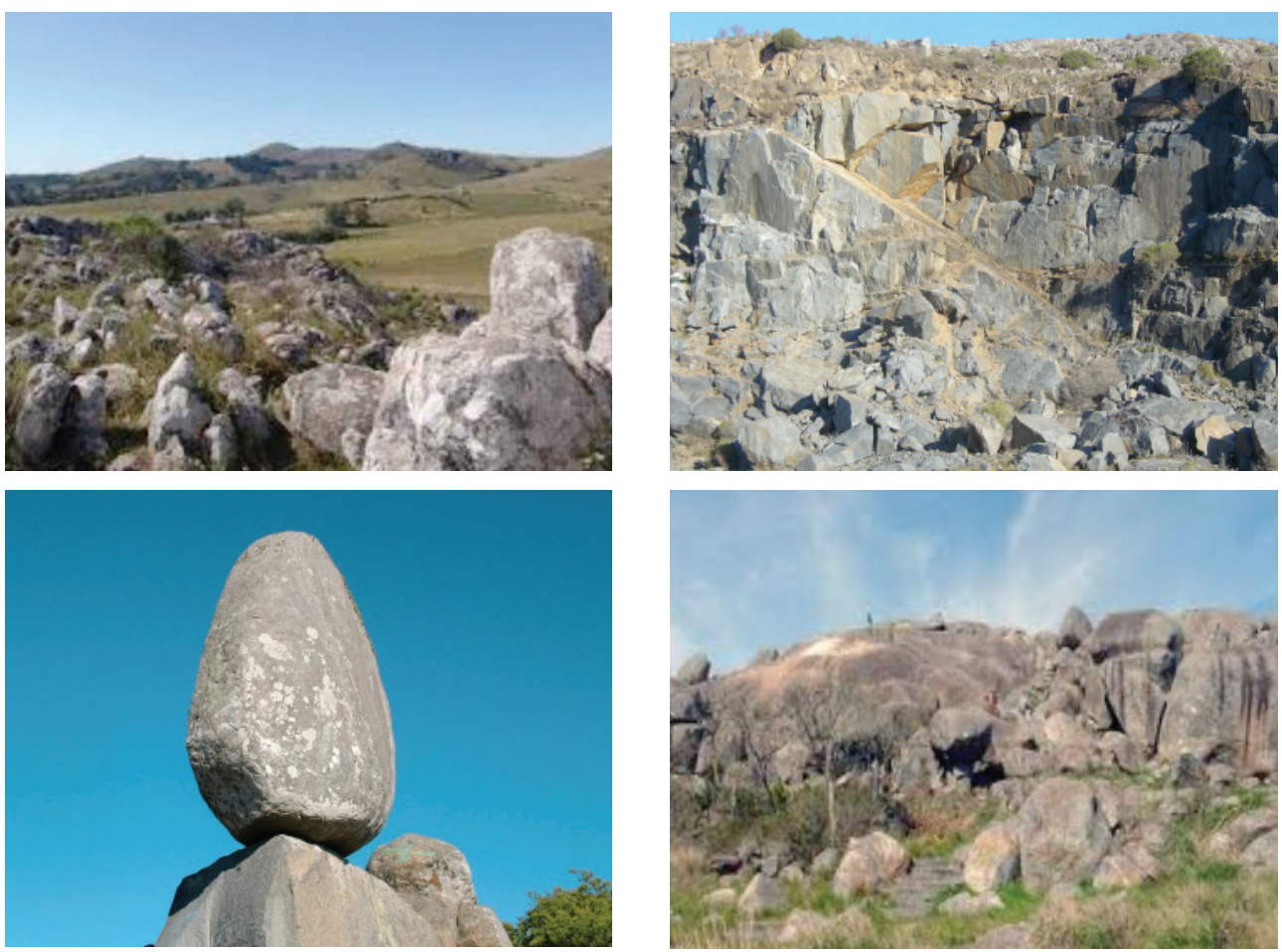

Fuente: Archivo personal, 2014.

edad paleozoica inferior. Por último, hay sedimentitas cuaternarias. Entre el basamento cristalino y las unidades sedimentarias se han desarrollado saprolitos arcósicos y cuarzocaoliníticos, previa sedimentación marina, los cuales indican niveles de paleometeorización. Esta cubierta sedimentaria contiene estromatolitos, biopelículas, trazas fósiles, acritarcas y probables invertebrados calcáreos ("shelly fauna") como únicas evidencias de la biocenosis que habitó los mares del Precámbrico y el Paleozoico en esta región del margen occidental de Gondwana (Dalla Salda, Spalletti, Poiré, De Barrio, Echeveste y Benilgo, 2006).

La rocas que pueden observarse en la zona son granitoides (de edad dominante paleoproterozoica transamazónica; se encuentran emplazadas en metamorfitas, usualmente parcial o casi totalmente migmatizadas, y en consecuencia presentan relaciones de campo frecuentemente difíciles de establecer; los granitoides poseen, en general, una filonación cuarzo-feldespática aplo-pegmatítica), milonitas, metamorfitas (esquistos, gneises, anfibolitas y mármoles) y rocas de filón (diques ígneos).

Los rasgos geomorfológicos de Tandilia se han originado como consecuencia del ataque erosivo sobre los bloques algo inclinados de las sierras, que presentaban dos pendientes de distinta inclinación, y dos tipos de rocas (de basamento y de cubierta) de diferente comportamiento frente a la denudación. Los bloques más altos de la porción central sufrieron la eliminación completa de la cubierta ortocuarcítica, razón por la cual las rocas granitoides quedaron directamente expuestas a la acción meteorizante. 
Individualmente, las formas de sierras y cerros graníticos están controladas por la esquistosidad y/o los planos de fallas y diaclasas. La exfoliación esferoidal o descamación se muestra también activa en escala mucho menor, pues es la causante del redondeamiento in situ de bloques y peñones, también como resultado de la descamación de un bloque irregular (piedra movediza caída en 1912) (Teruggi, Kilmurray, Rapela \& Dalla Salda, 1974).

En Tandilia se reconocen largas y amplias zonas de cizalla que afectan las rocas del basamento cristalino, por ejemplo, al sur de la ciudad de Tandil. Estas fajas de cizalla están compuestas por milonitas, protomilonitas y cataclasitas; estas últimas se ubican principalmente en los laterales y tabiques menos deformados dentro de las zonas de cizalla (Dalla Salda, Spalletti, Poiré, De Barrio, Echeveste y Benilgo, 2006).

\section{Resultados de la valoración de las áreas a partir de los índices}

De la tabla siguiente se desprende que en relación con el patrimonio minero y geológico, no existen sitios que puedan ser desestima- dos. Un $69 \%$ de los sitios tiene de mediano a alto valor, a priori, dentro del inventario, por su representatividad, estética y atributos. En tal sentido, el cerro Centinela, Movediza y la Reserva Municipal ostentan la mayor representatividad o diversidad de elementos. Junto con la valoración de uso potencial, estos espacios mantienen la representatividad, y en este aspecto la Reserva adquiere la mayor valoración.

Todos los espacios que presentan los valores más altos tienen actualmente actividad turística, mientras que los espacios asociados a la minería no.

Es importante indicar que más del $50 \%$ de los sitios inventariados y de sus recursos descriptos tiene potencialidad elevada de uso. Esto los ubica en un lugar muy interesante para el fortalecimiento de un parque geominero. Restando valor a esto, se evidencian las amenazas que solo son altas en uno de los sitios, que requiere evaluaciones específicas. Particularmente, el avance de la urbanización y la presión inmobiliaria y de infraestructura se convierten en amenazas o hechos concretos que ponen en riesgo la desaparición de los túneles subterráneos de extracción de arena.

Tabla 1. Índices aplicados a las áreas de estudio

\begin{tabular}{|l|c|l|c|l|c|l|c|}
\hline & IPMG & Valoración & IVP & Valoración & IA & \multicolumn{1}{|c|}{ Valoración } & IJP \\
\hline Cerro Leones & 3,2 & media & 4 & alta & 2,9 & media & 4.3 \\
\hline Co. Movediza & 3,9 & alta & 4,6 & alta & 1.5 & despreciable & 7 \\
\hline Ca. Nogales & 2,1 & baja & 2,2 & baja & 3.4 & media & 0.9 \\
\hline Co. Centinela & 4.1 & alta & 4,6 & alta & 1.5 & despreciable & 7.2 \\
\hline Ca. La Aurora & 2,8 & media & 3,8 & alta & 3.2 & media & 3.4 \\
\hline Reserva Natural Sierra del Tigre & 3.6 & alta & 5 & alta & 1.2 & despreciable & 7.4 \\
\hline Ca. Interlen & 2,1 & baja & 2,7 & media & 3.4 & media & 1.4 \\
\hline Ca. Carba & 2,8 & media & 3 & media & 3.4 & media & 2.4 \\
\hline Minas de arena & 2,7 & media & 2,4 & baja & 4.2 & alta & 0.9 \\
\hline
\end{tabular}

Fuente: elaboración propia. 
Este tipo de hechos también afecta en menor grado a otros sitios dentro de Tandil. Independiente de la situación que supone, hay riesgos que estos lugares atañen para la población al no estar remediados, tratados o planificados, en particular todos los sitios mineros, cavas, frentes, escombreras, etc.

Del índice final se observan tres sitios claramente destacados, que coinciden con los antes mencionados, actualmente en uso, no vinculados aún a la geodiversidad ni aspectos recreativos convencionales y apreciación del paisaje.

En general, no se observa vínculo con el patrimonio geológico directo, a pesar de la singularidad geológica del sistema de Tandilia, y menos aún del patrimonio minero, sobre todo de la etapa artesanal. En el extremo opuesto se encuentran los sitios mineros abandonados, con potencial, con valor científico y educativo diverso, complementarios entre sí, pero amenazados por intereses especulativos y, a su vez, generadores de situaciones de riesgo de seguridad de la población.

\section{Conclusiones}

Los parques geomineros pueden ser una estrategia al momento de implementar soluciones a espacios mineros abandonados total o parcialmente, y que en este caso comienzan a generar una serie de problemáticas relacionadas con la contaminación, la degradación del espacio urbano y periurbano, la inseguridad, los usos no permitidos, etc. De esta forma, los parques geomineros permitirían revalorizar estas áreas desde una perspectiva turísticorecreativa, además de dotar de significado al territorio.

Este trabajo, si bien se vincula a diferentes investigaciones llevadas a cabo por el grupo de trabajo del CINEA (Centro de Investigaciones y Estudios Ambientales) de la Facul- tad de Ciencias Humanas, es preliminar en torno a la propuesta concreta sobre la que actualmente se trabaja para desarrollar un proyecto de parque geominero para Tandil. De la evaluación realizada es posible decir que el territorio donde se encuentra la ciudad de Tandil presenta un rico patrimonio minero, producto de más de un siglo de actividad, la cual ha dejado una fuerte impronta, desde viviendas de piedra y restos de la etapa picapedrera de fines del siglo XIX, hasta maquinarias, galpones y viviendas de mitad y fines del siglo Xx. Por otro lado, desde la perspectiva de la geodiversidad, la región presenta singularidades relacionadas con su larga historia geológica, con la diversidad de las rocas y con la existencia de un basamento cristalino expuesto.

A este rico patrimonio y geodiversidad se suma que Tandil es un destino turístico en crecimiento que necesita fuertemente mantener la competitividad mediante el desarrollo de nuevos productos turísticos, y en este sentido, el geoturismo podría ser una modalidad que podría cumplir este objetivo.

Este contexto integrado por el patrimonio minero, la geodiversidad y el geoturismo es factible de plasmar por medio de la creación de un parque geominero que articule y conecte los sitios, y que permita así un desarrollo integrado, articulado y sustentable.

\section{Bibliografía}

Betancurth, L. (2003). El patrimonio geológicominero del eje cafetero, cuenca del rio Chinchiná - Colombia. En R. C. Villas-Bôas, A. González Martínez, G. de A. Sá y C. de Albuquerque (Eds.), Patrimonio geológico y minero en el contexto del cierre de minas. Río de Janeiro: CNPq/CYTED.

Cañizares Ruiz, M. (2011). Protección y defensa del patrimonio minero en España. Scripta Nova. Revista Electrónica de Geografía y Ciencias 
Sociales, XV(361). Recuperado de http://goo. gl/8yeh5u

Carcavilla, L., Durán, J. J. y López-Martínez, J. (2008). Geodiversidad: concepto y relación con el patrimonio geológico. Geo-Temas, 10, 1299-1303. VII Congreso Geológico de España. Las Palmas de Gran Canaria.

Dalla Salda, L., Spalletti, L., Poiré, D., De Barrio, R., Echeveste, H. y Benialgo, A. (2006). Tandilia. INSUGEO, Serie Correlación Geológica, 21(1), 17-46.

Dirección General de Gestión del Medio Natural, Consejería del Medio Ambiente y Junta de Andalucía. (2010). Estrategia andaluza de gestión integrada de la geodiversidad. Andalucía: Consejería del Medio Ambiente. Recuperado de http://goo.gl/nCbxO9

Cueto Alonso, G. (2009). Reutilización turística del patrimonio minero de Cantabria. Cuadernos de Turismo, 23, 69-87.

Hose, T.A. (1997). Geotourism - Selling the Earth to Europe. En K. Marinos, \& T. Stournaras (Eds.), Engineering Geology and the Environment (pp. 2955-2960). España: Balkema Rotterdam.

Hose, T. A. (1995). Selling the Story of Britain's Stone. Environmental Interpretation, 10(2), 16-17.

Instituto Nacional de Ecología (INE). (2004). El establecimiento de geoparques en México: un método de análisis geográfico para la conservación de la naturaleza en el contexto del manejo de cuencas hídricas. México: Autor.

Instituto Nacional de Estadística y Censos (INDEC). (2012). Censo Nacional de Población, Hogares y Viviendas 2010. Censo del Bicentenario. Resultados definitivos. Serie 8, n. $^{\circ} 2$. Buenos Aires, Argentina: INDEC.

Iñiguez Rodríguez, A., Del Valle, A., Poiré, D., Spalletti, L. y Zalba, P. (1989). Cuenca precám- brica-paleozoica inferior de Tandilia, Provincia de Buenos Aires. En G. Chebli \& L. Spalletti (Eds.), Cuencas sedimentarias argentinas. Serie Correlación Geológica 6 (245-263). Argentina: Instituto Superior de Correlación Geológica y Universidad Nacional de Tucumán.

Manosso, F. C. (2012). Potencial del geoturismo y la geodiversidad en la Serra do Cadeado, Paraná, Brasil. Estudios y Perspectivas en Turismo, 21, 322- 338 .

Moreira, J. C. (2010). Geoturismo: uma abordagem histórico-conceitual. Pesquisas em Turismo e Paisagens Cársticas, 3, 5-10.

National Geographic Society. (2011). Declaración de Arouca. Presentada en el Congreso Internacional de Geoturismo - Geotourism in Action - Arouca 2011. Arouca Geopark, Portugal.

Nieto, L. M. (2001). Geodiversidad: propuesta de una definición integradora. Boletín Geológico y Minero, 112(2), 3-12.

Orche, E. (2003). Puesta en valor del patrimonio geológico-minero: el proceso de adaptación de explotaciones mineras a parques temáticos. En R. C. Villas-Bôas, A. González Martínez, Gildo de A. Sá y C. de Albuquerque (Eds.), Patrimonio geológico y minero en el contexto del cierre de minas. Río de Janeiro: CNPq/CYTED.

Orche, E. (2001). La función multidisciplinar de los parques geomineros. Trabajo presentado en la v Reunión Nacional de la Comisión de Patrimonio Geológico, Molina de Segura (Murcia, España). Recuperado de http://goo.gl/GDskw7

Rendón Rivera, A., Henao Arroyave, A. y Osorio Cachaya, J. (2013). Propuesta metodológica para la valoración del patrimonio geológico como base para su gestión en el departamento de Antioquia Colombia. Boletín Ciencias de la Tierra, 33, 85-92.

Santana, A. (2003). Editorial. Patrimonios culturales y turistas: Unos leen lo que otros miran. En 
Pasos. Revista de Turismo y patrimonio cultural, 1(1), 1-12.

Schilling, M. et al. (2010). Hacia la creación de la red de geoparques de Latinoamérica. Trabajo presentado en el XV Congreso Peruano de Geología. Sociedad Geológica del Perú, Cusco. Resúmenes Extendidos, 9, 282-286.

Serrano Cañadas, E. y Ruiz Flaño, P. (2007) Geodiversidad: concepto, evaluación y aplicación territorial. El caso de Tiermes Caracena (Soria). Boletín de la A.G.E., 45. 79-98.

Teruggi, M. \& Kilmurray, J. (1980). Sierras septentrionales de la provincia de Buenos Aires.
En Anales II Simposio de Geología Regional de Argentina (pp. 919-965). Córdoba: Academia Nacional de Ciencias.

Teruggi, M. E., Kilmurray, J. O., Rapela, C. W. y Dalla Salda, L. (1974). Diques básicos en las Sierras de Tandil. Revista de la Asociación Geológica Argentina, 29(1), 41-60.

Voth, A. (octubre de 2008). Los geoparques y el geoturismo: nuevos conceptos de valorización de recursos patrimoniales y desarrollo regional. Trabajo presentado en el XI Coloquio Ibérico de Geografía, Alcalá de Henares. Recuperado de http://goo.gl/bDi9yB 